\title{
REFLEXÕES CRÍTICAS ACERCA DA PSICOLOGIA EXISTENCIAL DE ROLLO MAY
}

\author{
Critical Reflexions Concerning on Existential Psychology of Rollo May \\ Reflecciones Críticas de la Psicología Existencial de Rollo May
}

Carlos Roger Sales da Ponte

HudsSOn Lima DE Sousa

\begin{abstract}
Resumo: Partindo do pressuposto de que Rollo May é um psicólogo geralmente esquecido nas terras brasileiras, este breve estudo teórico de uma pesquisa em andamento objetiva dar novo conhecimento deste eminente psicólogo. Para tanto, mostramos um breve esboço biográfico de May e de um histórico da Psicologia Humanista nos EUA; resgatamos algumas influências epistemológicas de seu pensamento, descrevemos as temáticas ligadas ao conceito de Inconsciente e a concepção de humano em May a fim de fornecermos alguns delineamentos da Psicologia Existencial por ele construída.
\end{abstract}

Palavras-chave: Rollo May; Psicologia Existencial; Psicologia Humanista; Epistemologia das Psicologias.

Abstract: Assuming that Rollo May is a psychologist usually forgotten in the land of Brazil, this short theoretical study of going research aims to provide new knowledge of this eminent psychologist. To this end, we show a brief biographical sketch of May and a history of Humanistic Psychology in the U.S.; rescued some epistemological influences of his thinking, we describe the issues related to the concept of the Unconscious and the concept of human in May to provide some guidelines of Existential Psychology built for him.

Keywords: Rollo May; Existential Psychology; Humanistic Psychology; Epistemology of Psychologies.

Resumen: Suponiendo que Rollo May es un psicólogo olvidardo en la tierra de Brasil, este breve estudio teórico de una investigación en curso tiene como objetivo proporcionar nuevos conocimientos de este eminente psicólogo. Con este fin, se muestra una breve semblanza de May y una historia de la Psicología Humanística en los EE.UU., rescatamos algunas influencias epistemológicas de su pensamiento, se describen los problemas relacionados con el concepto de lo Inconsciente y el concepto de lo humano en May para dar algunas pautas de la Psicología Existencial por él construida. Humanística Palabras-clave: Rollo May; Psicología Existencial; Psicología Humanística; Epistemología de las Psicologías.

"Rollo May também é um salvador do mundo" Abraham Maslow (Citado por Frick, 1975)

\section{Introdução}

Muito se escreveu e pesquisou sobre a história da Psicologia Humanista (suas, origens, suas características, visão do humano, epistemologia, pesquisas, perspectivas de futuro, etc.) e de alguns de seus expoentes mais conhecidos. Porém, percebemos que tal não acontece com outro importante nome: Rollo May.

Este breve estudo epistemológico intenta corrigir esta lacuna. Partindo da pressuposição de que Rollo May é um psicólogo geralmente esquecido nas terras brasileiras, objetivamos primeiramente dar a conhecer quem foi este eminente pensador por meio de uma breve biografia. Em seguida, esboçamos rapidamente um histórico da Psicologia Humanista nos EUA. Por fim, traçaremos uma série de comentários a algumas dimensões que sub- jazem à Psicologia Existencial de May, promovendo um rápido resgate de algumas influências epistemológicas de seu pensamento; descrevendo certas temáticas conceituais singulares deste psicólogo para podermos fornecer contornos mais nítidos da Psicologia Existencial por ele proposta.

É certo que não queremos mostrar exaustivamente o pensamento de May, e nem conseguimos cobrir a totalidade das temáticas por ele desenvolvidas neste breve estudo. Em tempos que muito se discute e constrói-se interrelações entre Psicologia Humanista e as Filosofias da Existência, pretendemos aqui provocar o diálogo e convidar ao mergulho radical na psicologia existencial-humanista de Rollo May: uma psicologia prenhe de contribuições para uma compreensão mais alargada e profunda do humano em suas várias nuances existenciais, recheada de interseções e atalhos ricos para que possamos construir nossa próprias reflexões e práticas. 


\section{Esboço Biográfico ${ }^{1}$}

Rollo May nasceu em 21 de abril de 1909 em Ada, Ohio, EUA. Após uma infância particularmente conturbada por conta da convivência difícil de seus pais, ao se tornar estudante universitário na Universidade de Michigan, trabalhou durante algum tempo numa revista estudantil de perfil radical. Ao que parece, trabalhar neste periódico acarretou-lhe problemas junto à Universidade sendo expulso desta instituição. Foi para a Faculdade de Oberlin, Ohio, e ali se graduou em Artes em 1930.

Motivado que estava pelo campo das artes, May viajou para a Grécia onde se revezava entre o ensino de inglês na Universidade de Anatólia e excursões pelas aldeias camponesas gregas com um grupo de artistas, esmerando-se em desenho e pintura. Permaneceu na Grécia por três anos. Durante a estadia na Europa, May também teve tempo de estudar brevemente em Viena com Alfred Adler, o qual, desde 1911, havia abandonado a psicanálise freudiana e constituído sua Psicologia Individual.

Ao retornar para os EUA, May, ingressou no Union Theological Seminary de New York, prestigiada instituição religiosa de caráter liberal (Carl Rogers já havia sido estudante deste Seminário dez anos antes) e onde lecionava, desde 1933, o conhecido teólogo e filósofo alemão Paul Tillich, de quem se tornou amigo até a morte deste em 1965.

A graduação de May em Teologia foi completada em 1938 quando tinha 29 anos. Antes de deixar o Union Theological Seminary, May teve de interromper seus estudos temporariamente para cuidar de assuntos familiares que necessitavam sua atenção.

Completado seus estudos, May começou a trabalhar como ministro da Igreja Congregacional em New Jersey. Na condição de homem religioso e próximo de seus fiéis, May constituiu-se um "conselheiro", empreendendo uma reflexão acurada no modo como lidar com as pessoas em situação de aconselhamento. May apontava para a necessidade de se perceber a pessoa como um todo, ali em atendimento, e como deve o aconselhador relacionar-se com esta pessoa e não com o seu "problema". Ressalta inclusive a importância da empatia como

\footnotetext{
A biografia de Rollo May não está bem organizada e devidamente referendada em terras brasileiras. Pelo menos, a partir das fontes que dispomos. Isto posto, este breve esboço biográfico teve por base, além das obras citadas, o texto disponível na internet de Serrano (2008); em outros dois sites (http://www.oocities.com/eduriedades/ rolloMay.html; http://mythosandlogos.com/May.html) e de várias conversas com Paulo Coelho Castelo Branco, psicólogo estudioso da Psicologia Humanista e Professor Assistente do Curso de Psicologia da Faculdade Leão Sampaio (Juazeiro do Norte/CE), a quem agradecemos ter compartilhado seu conhecimento conosco. Assim, pedimos desculpas se algumas das fontes não parecem ser tão seguras para falar da vida deste eminente psicólogo. Esperamos que esta nossa contribuição seja bem mais substancial do que até agora foi feito.
}

processo-chave nesta relação de ajuda. Sem dizerse "psicoterapeuta" (já que efetivamente não era) e influenciado pelo que aprendera com Adler, Otto Rank e a psicanálise freudiana, o resultado destas experiências tomará corpo em 1938 com a publicação de seu primeiro livro, A Arte do Aconselhamento Psicológico. $^{2}$

Quando voltou para New York iniciou uma formação mais sólida e aprofundada em psicanálise (na verdade, em abordagens psicológicas neo-freudianas) no William Alanson White Institute of Psychiatry, Psychology and Psychoanalysis, onde travou contato com os enfoques culturalistas de Harry Stack Sullivan e Erich Fromm. Mas foi na Universidade de Columbia que ele recebeu seu doutorado em psicologia clínica em 1949. Suas incursões filosóficas sobre o drama humano existencial começavam a ficar cada vez mais incisivas. Uma mostra disto está na sua obra, publicada em 1953, O homem à procura de si mesmo (MAY, 1999).

Enquanto trabalhava no seu Doutorado (cujo resultado foi o seu $3^{\circ}$ livro, O Significado $d a$ Ansiedade, publicado em 1950), que May contraiu tuberculose, passando 1 ano e meio internado em um hospital, posto que naquela época o desenvolvimento de antibióticos no combate à tuberculose ainda estavam em seus estágios iniciais e a cura (ou não) do paciente dependia somente de constantes cuidados médicos.

Ele nos conta que, enquanto se deparava com a possibilidade de morrer, tendo "um vasto tempo para ponderar sobre o significado da ansiedade - além de inúmeros dados em primeira mão colhidos de mim mesmo e de meus ansiosos companheiros pacientes" (May, 1988, p. 15), ocupava seu tempo com a leitura de dois livros: O Problema da Ansiedade de Freud (este livro, na verdade, é uma tradução norte-americana do texto Inibição, Sintoma e Angústia) e O Conceito de Angústia de Kierkegaard. Embora percebesse as claras divergências entre as concepções de Freud e de Kierkegaard (o primeiro, a partir de uma descrição mais técnica dos mecanismos psíquicos os quais manifestam a angústia; o segundo, o significado, o sentido existencial e ontológico da angústia como um conflito entre ser e não-ser, entre o finito e o eterno, sem jamais encontrar uma síntese ou paz), May não desprezou nem um nem outro. De todo modo, pode-se imaginar os sentimentos de pavor que acometiam May ao ver outros pacientes ocasionalmente morrerem ao seu lado com relativa frequência. Isso deve tê-lo deixado mais

\footnotetext{
Semelhante perspectiva acerca do atendimento terapêutico já começava a configurar-se nas observações clínicas de Carl Rogers, o qual, em breve, inauguraria sua Terapia NãoDiretiva com o livro Psicoterapia e Consulta Psicológica, publicado em 1942. Mas não é uma simples coincidência. Rogers leu o livro de May, conforme pode ser visto na Bibliografia Escolhida que figura no final desta obra inaugural.
} 
sensível a esta “disposição fundamental” que é a angústia (May, 1980).

Assim, os inícios da Psicologia Existencial de Rollo May, relacionam-se com a não só com a angústia enquanto problema conceitual, psicológico, mas como vivência e ciência irmanadas. Incluam-se aí leituras cada vez mais originais e ousadas da psicanálise freudiana. Como ele mesmo atesta,

(...) o enfoque existencial não tem o objetivo de rejeitar as descobertas técnicas de Freud ou daqueles de qualquer outro ramo da psicologia. Procura, no entanto, situar estas descobertas sobre novas bases, dando uma nova compreensão, redescobrindo a natureza e a imagem do ser humano (May, 1988, p. 17).

Mesmo com as gritantes diferenças entre estes autores (Freud e Kiekegaard), May, como se disse, não fez escolha entre eles. E diferente de outros psicólogos humanistas que tendiam a desprezar os achados psicanalíticos, May agrega os dois pontos de vista como necessários (May, 1980). Tais experiências fizeram com que May se alinhasse cada vez mais a uma concepção de psicologia de cunho fortemente existencial, fazendo-o aprofundar-se cada vez mais nesta corrente filosófica. Tanto foi assim que em 1958, May organizou juntamente com Ernst Angel e Henri Ellenberger, o livro Existence: a nem dimension in psychatry and psychology (May, Angel \& Ellenberger, 1977), obra de referência que difundiu com maior ênfase as ideias e pesquisas em termos de uma psicologia e uma psicopatologia existencial de cunho fenomenológico.

Depois daí a vida pessoal, profissional e a reflexão de May não cessou de serem frutíferas: exerceu durante anos a atividade de psicoterapeuta existencial, o que enriquecia seus questionamentos concernentes às dimensões trágicas e às potencialidades do humano: o humano como constituidor de valores e como este "valorar" afeta a existência (May, 1977); as relações amorosas e a questão da vontade (May, 1973); a dinâmica da criatividade e da arte (May, 1992a); a discussão entre destino e liberdade (May, 1987); sobre a arte e a beleza (May, 1992b). Esta obra em particular é um fruto tardio de suas reflexões daqueles anos em que estivera na Grécia após estudar artes) e acerca dos mitos (May, 1992c). May ainda lecionou em Universidades como a de New York, Harvard, Yale e Princeton.

Rollo May viveu seus últimos anos em Tiburon, Califórnia, falecendo em 22 de outubro de 1994, aos 85 anos. Como se viu, a trajetória de Rollo May como psicólogo existencial o fez convergir com o ideário da Psicologia Humanista dos EUA. Porém, como ele entra na constituição desta forma de fazer e pensar a psicologia, para depois comportar uma certa diferença em relação à mesma? Uma rápida caracterização histórica da Terceira Força se faz necessária para responder esta pergunta.

\section{O Surgimento da Psicologia Humanista}

A Psicologia Humanista fez seu aparecimento nos EUA no final dos anos 50 e início dos anos 60, com as primeiras publicações de Abraham Maslow sobre a motivação no estudo da personalidade e a consequente formulação do conceito de autorrealização. Esta psicologia foi se desenvolvendo, não apenas pela continuidade das pesquisas de Maslow, mas com a adesão de outros nomes (entre eles, Carl Rogers, Rollo May, Gordon Allport, Charlotte Bühler, etc.) cujos trabalhos, apesar de comportarem diferenças metodológicas e conceituais, se alinhavam em diversas premissas semelhantes.

Havia também uma forte insatisfação com o modelo do humano proporcionado pelo Behaviorismo, ainda sob forte influência de Watson, e pela Psicanálise proposta por Freud. No entender dos primeiros psicólogos humanistas, a Psicanálise e o Behaviorismo eram enfoques por demais reducionistas, mecanicistas e deterministas acerca do humano em detrimento de valores exclusivamente humanos, como a criatividade, a liberdade, a decisão e a escolha, etc. (Carpintero, Mayor \& Zalbidea, 1990). Mas vejamos melhor como isso se deu.

Na década de 50, Maslow - que era professor de psicologia na Universidade de Brandeis -, possuía interesses pouco ortodoxos em pesquisa e sentia dificuldades para publicar seus artigos que não possuíam o referencial teórico adotado pela maioria dos periódicos vigentes, o que lhe proporcionou um certo isolamento profissional e intelectual. Da necessidade de contornar a dificuldade de publicação e a troca de conhecimentos, Maslow organizou, em meados da década, uma lista de psicólogos (a Rede Eupsiquiana) que compartilhavam com ele ideias menos tradicionais em psicologia e que se preocupavam com questões ligadas a saúde psicológica do humano (Boainain Jr, 1998).

Com o volume das discussões que se vinham produzindo na Rede Eupsiquiana eles perceberam que já podiam fundar uma revista própria. Após várias discussões sobre os nomes possíveis para esta publicação, em 1961 o nome escolhido foi Journal of Humanistic Psychology, sugerido por Sidney Cohen. E com o sucesso da Revista, em 1963, surge a American Association for Humanistic Psychology (fundada por Abraham Maslow, Charlotte Bühler e Rollo May) e em 1964, ocorre na cidade de Old Saybrook uma grande conferência que reunirá os principais nomes da Psicologia Humanista que serviram de inspiradores deste movimento que então se inaugurava (Boainain Jr, 1998). Reunidos por uma Associação e com uma publicação própria, o movimento humanista em psicologia "concede prioridade à validez da experiência humana, aos valores, intenções e significados da vida" (Carpintero, Mayor \& Zalbidea, 1990, p. 71). ${ }^{3}$

Todas as traduções do texto de Carpintero; Mayor \& Zalbidea, 1990, são de nossa inteira responsabilidade. 
Os psicólogos que aderiram a Psicologia Humanista eram diversificados em interesses e em pensamentos, sem um expoente inicial, constituindo um grupo de diversas tendências que, no geral, se opunham à Psicanálise e ao Behaviorismo. Assim "ao contrário das forças anteriores, a Psicologia Humanista não se identifica ou inicia com o pensamento de determinado autor ou escola" (Boainain Jr, 1998, p. 24). Do ponto de vista histórico, todavia, concorda-se que Maslow foi, com toda propriedade, o aglutinador destes vários pensadores e psicólogos, o principal nome de referência na fundação da Psicologia Humanista, além de ter cunhado a expressão “Terceira Força” (Carpintero, Mayor \& Zalbidea, 1990).

Entre as influências que se aproximam da Psicologia Humanista, podemos ver os psicanalistas dissidentes de Freud (Adler, Rank e Jung) que são vistos com bons olhos pelos humanistas. Uma vez que os psicanalistas dissidentes já possuem suas críticas ao modelo freudiano de psicopatologização, impessoalidade técnica e visão pessimista do homem, eles forneceram confluências com a psicanálise e insights a vários dos humanistas clássicos (Boainain Jr, 1998). Vale incluir nesta lista os psicanalistas Erich Fromm e Karen Horney

Os humanistas clássicos também se apropriaram de propostas da Psicologia da Gestalt, utilizando-se fortemente da visão holista de humano que também vigorava no interior desta vertente psicológica; as Teorias da Personalidade criadas em solo norte-americano (Allport, Murray, Murphy e Kelly); a Psicologia Organísmica de Goldstein e as psicologias existenciais européias de Binswanger, Boss, Van Kaam e da sua versão americana criada por Rollo May. (Carpintero, Mayor \& Zalbidea, 1990).

Com tal miríade de componentes epistemológicos, o humanismo em psicologia percebia a natureza humana como

(...) positivamente orientada, devendo as relações deletérias ser responsabilizadas por qualquer desvio dessa bondade original. Para os existencialistas, sendo o homem livre e auto-orientado pelos propósitos e sentidos que dá a própria existência, não pode eximir-se de se responsabilizar plenamente [...], pois qualquer outra atitude seria auto-engano, má fé, inautenticidade no existir (Boainain Jr, 1998, p. 33).

Como qualquer acontecimento histórico de peso, o surgimento e desenvolvimento da Psicologia Humanista também se vinculam às "características sócias e aos valores sociedades ocidentais na década de sessenta, e em particular, da sociedade americana" (Carpintero, Mayor \& Zalbidea, 1990, p. 76). E isto significa um forte questionamento advindo de várias camadas sociais acerca do modo como se conduzia a vida humana: uma busca desenfreada de sucesso financeiro a qualquer custo, o domínio bélico de países sobre outras nações, a economia que começava a tomar contornos globais que afetavam a vida humana e a vida do planeta como um todo. Estas inquietações existenciais motivaram vários movimentos para a "busca de novos horizontes políticos e éticos que abriram andamento a aspirações de riqueza e qualidade de vida mais genuína, colaboraram de modo fundamental a configurar o contexto social, coletivo, que propiciou o nascimento da Psicologia Humanista" (Carpintero, Mayor \& Zalbidea, 1990, p. 77). Em tal contexto desencadeou o movimento da Contracultura.

Dentro deste movimento, os jovens "queriam mudar o mundo. Perguntava-se como se poderia torna o mundo mais humano, melhor de se viver, menos insensato" (Campos, 2006, p. 243). Este contexto permitia o surgimento e perpetuação de uma psicologia em que se buscava um aumento exponencial das potencialidades humanas, e que valia a pena tentar atingir este objetivo. Neste período também estava muito em voga o interesse por modelos orientais de vida e a Psicologia Humanista acabou por ser também usada como "ferramenta" nesta busca (um nome que teve uma grande intimidade por tais modelos foi, por exemplo, Fritz Perls).

Até meados da década de 70, este movimento contracultural foi altamente turbulento, pois os jovens eram marcadamente rebeldes e promoviam revoltas contra toda a estrutura social que então vigorava. Estes atos surgiram em várias partes do mundo, tendo como mote principal serem contra a desumanização do humano em geral. No entender dos ativistas, nada estava bom, desde a prática política até o menor dos costumes (incluindo aí os costumes sexuais). Tudo precisaria ser reinventado. Tinha-se o sonho de que o mundo poderia mudar para melhor pela via da união e da luta política (Campos, 2006).

$\mathrm{Na}$ busca de outro tipo de mentalidade (bem entendido, outro tipo de consciência), estimulou-se o uso de drogas alucinógenas (como o LSD) e os ídolos da música (como os Beatles, os Rolling Stones, The Doors, mas também Bob Dylan, Jimi Hendrix e Janis Joplin poderiam ser incluídos neste rol) foram elevados à condição de exemplos de conduta pessoal. O lema sexo, drogas e rock'n'roll fazia todo o sentido (Campos, 2006).

Dentro de uma perspectiva política, os jovens admiravam líderes como Mao Tsé-Tung (com a Revolução Cultural Chinesa), Ernesto "Che” Guevara e Fidel Castro (com a Revolução Cubana) pelo empenho que eles dedicavam a um modo de construção social diferente ao status de vida apregoado pelo capitalismo. Isso sem falar da repercussão da Primavera de Praga, em 1968, que defendia um socialismo com uma face mais humanizada, e as consequências funestas da longa Guerra do Vietnã.

Nos EUA, pessoas como Martin Luther King (pastor protestante que se tornou líder do ativismo político pelos direitos civis dos negros), Malcolm X (de orientação islâmica e também defensor dos direitos políticos dos 
negros) e a atividade político-partidária dos Panteras Negras também eram alvos de elogios e veneração da juventude daquela década.

Na perspectiva filosófica, o pensamento de Herbert Marcuse, com sua crítica da sociedade capitalista e do homem unidimensional, e a Escola de Frankfurt, tornaram-se os referenciais constituidores dos protestos contra a toda a estrutura social vigente. Pensava-se o seguinte: para que fosse promovida uma mudança externa (social), primeiro deveria advir uma mudança interna (psicológica). Todavia, logo perceberam que essa mudança de "atitudes mentais" como algo prévio a uma revolução social era algo grande demais. Assim, os revoltosos dos anos 60 reduziram seu raio de ação do "social" para o âmbito do psíquico a fim implantar as mudanças que tanto almejavam. Todo este contexto também se encontrava na base das ideias humanistas (Campos, 2006).

No entender de Campos (2006), todo este clima sóciocultural dos anos 60 foi o principal suporte sócio-cultural que preparou, tanto o terreno para a emergência da Psicologia Humanista, como seu desenvolvimento posterior. Escreve ele que

(...) de um certo modo, estão "dadas" as condições para o surgimento do projeto de psicologia humanista. No meu entendimento, o clima cultural dos anos 60 foi a principal condição de possibilidade para a constituição dessa proposta de psicologia. Essa psicologia será uma resposta, fará eco ao movimento cultural dos anos 60 nos EUA (Campos, 2006, p. 249).

Essas vivências que ajudaram a Contracultura, todavia "estimulou o estudo, a experimentação e a aplicação - infelizmente de modo nem sempre tão serio e criterioso como seria de se desejar - de novas formas de ajuda psicológica" (Boainain Jr, 1998, p. 27). Desta forma com o fortalecimento da Contracultura, fortalecia-se a Psicologia Humanista e vice versa. Entretanto, nem sempre de forma tão simétrica.

Assim, a Psicologia Humanista, dentro do momento dos EUA nas décadas de 60 e 70, nada mais foi do que uma das respostas aos apelos daqueles anos turbulentos. Ela tinha como fios condutores básicos uma crítica ao modelo científico que vigorava até então em psicologia (de inspiração positivista e tendo as ciências naturais como modelos de como se fazer ciência) e uma perspectiva acerca do humano como livre e responsável.

Devemos ressaltar, contudo, o quanto foi convergente o fortalecimento da Contracultura com a Psicologia Humanista sendo ela muitas vezes vistas como uma faceta daquele momento histórico. Pode-se afirmar, com esta caracterização histórica, que uma das tônicas do humanismo em psicologia em acordo com o movimento da Contracultura "é marcada por um compromisso de engajamento em favor da mudança social e cultural em direção a uma sociedade de valores mais humanos (...)"
(Boainain Jr, 1998, p. 28). Os jovens sentiam-se na necessidade de inventar novas propostas de vida, outros padrões familiares novos costumes sexuais. A Contracultura em suas contestações,

(...) não contavam com nenhuma espécie de dirigentes, nem estiveram ligados a nenhum partido político; os jovens desse período contestavam inclusive os profissionais da contestação. Esses jovens estavam unidos por afinidades e não por cumplicidade. Tratava-se, naquele momento, de combater uma sociedade que se vinha constituindo como meramente tecnocrática [...] privilegiando os aspectos técnicos-racionais, em detrimento dos sociais e humanos (Campos, 2006, p. 242).

Percebemos que a proximidade político-ideológica da Contracultura estava também na base para os psicólogos humanistas, além da quebra da autoridade e a negação da tecnocracia como modelo de melhorar a condição humana. Aqui o humanismo vem colocar a importância da autodeterminação, ideia igualmente valorizada no movimento contracultural.

\section{Dimensões da Psicologia Existencial de Rollo May: epistemologia e temáticas}

Descrita a Psicologia Humanista em suas linhas históricas gerais, arriscamos desde já em dizer que Rollo May foi uma figura mais ou menos diferenciada dentro deste movimento, mesmo tendo sido um de seus membros fundadores. Também nele existe uma valorização do humano como detentor de potencialidades de crescimento e como uma totalidade existencial responsável por si mesma. Todavia, a nosso ver, May não cumpre todos os requisitos que o fariam se alinhar às fileiras desta Psicologia, parecendo que seu enquadramento no humanismo é mais por sua participação histórica na fundação do movimento. Some-se a isso o fato de que os interesses existencialistas e humanistas de May já vinham se construindo antes de Maslow constituir sua Rede.

A partir de tais dados, concordamos com Barrocas (s/d) de que May deve ser identificado como um psicólogo existencial-humanista, até pelo fato dele mostra-se muito mais bem fundamentado epistemologicamente do que Maslow ou Rogers, comentando e apropriando-se de autores aos quais faz clara referência. Percebemos, inclusive, e estranhamente, que, apesar da densidade de sua psicologia e seus constantes diálogos com a fenomenologia-existencial, suas ideias, repetimos, encontram-se bastante esquecidas nas paragens brasileiras quando se trata da estudar a história, a epistemologia dos enfoques humanistas em psicologia, bem como as intersecções entre fenomenologia e existencialismo. 


\section{Dimensões Epistemológicas}

Um primeiro ponto importante a que já aludimos e para se começar a compreender a psicologia de May, foi a marcada influência da filosofia em geral e, particularmente, das filosofias existenciais européias.

Este encontro foi proporcionado, em primeiro lugar, pelo forte contato com Paul Tillich quando May ainda era estudante no Union Theological Seminary.

Tillich dizia de si mesmo como sendo um teólogo de fronteiras, isto é, alguém que não poderia ser classificado ou inserido nesta ou naquela corrente de pensamento, posto que se enveredava em dialogar com várias teologias e filosofias, às vezes contraditórias entre elas, concedendo-lhe uma postura eclética. Influenciado fortemente por Kierkegaard e pela filosofia tardia de Schelling, Tillich teceu uma densa investigação teológica (com fortes tons luteranos e agostinianos) incorporando a "perspectiva filosófica do existencialismo, no sentido da tematização da existência humana no âmbito da subjetividade e da concretude" (Goto, 2004, p. 100). Interessado em audaciosos diálogos com outros saberes, também fez releituras da psicanálise freudiana a partir do seu prisma existencial. Por isso, Tillich este vê envolvido, nos anos 40, em debates com o New York Psychology Group (NYPG), em que "participaram vários pensadores de vanguarda da psicologia da época, dentre os quais se destacam Erich Fromm, Carl Rogers, Rollo May, Ruth Benedict, Seward Hiltner e David Roberts" (Silva \& Holanda, 2010, p. 72)

Este contato com o pensamento religioso-existencial de Tillich, e seus intercâmbios com a psicologia, terá um efeito intenso e marcante no pensamento e na obra de May que não cansou de citá-lo e comentá-lo. Podemos dizer, sem dúvida, que foi Tillich que apresentou o pensamento de Kierkegaard a May.

Tal familiaridade de May com o existencialismo lhe forneceu um modo diferente de perceber o humano em suas dimensões trágicas, além de vê-lo como, simultaneamente, padecendo de um dilema, ao mesmo tempo, entre ser sujeito e ser objeto. Dilema em que não se escolhe apenas um dos termos da questão, mas vivenciando-os enquanto pólos numa situação irresolvível de perene tensão (May, 1977). Só isso já começa a desviar-lhe dos caminhos psicanalíticos tradicionais, bem como da visão do humano (por vezes otimista demais) dos outros psicólogos humanistas como Rogers e Maslow, por exemplo; ou mesmo do cientificismo behaviorista dos anos 50 e 60.

No tocante à difusão das psicologias fenomenológicas-existências européias em solo norte-americano, Carpintero; Mayor e Zalbidea (1990) sustentam que não se pode defender que a fenomenologia teve influência direta nas obras de todos os criadores da Psicologia Humanista, ainda que muitos teóricos ligados ao pensamento exis- tencial ou gestaltista tenham migrado para os EUA em consequência da ascensão do nazismo na Europa.

De todo modo, pouco a pouco foi surgindo traduções para o inglês de algumas obras daqueles psicólogos europeus feitas por May e pela difusão do próprio Tillich. Ao disseminar aquelas psicologias em solo norte-americano, em 1959, dois anos antes da aparição do Journal of Humanistic Psychology, May organizar o primeiro Simpósio Americano de Psicologia Existencial que contaria com a presença dos futuros lideres do movimento humanista (Boainain Jr, 1998).

As marcas deixadas no espírito de May pelas filosofias da existência podem ser claramente percebidas no capítulo intitulado "Origens e Significado da Psicologia Existencial" de sua obra A Descoberta do Ser (May, 1988). Ali May discorre sobre tais influências sofridas em sua própria Psicologia Existencil. Podem-se ler nomes como Husserl, Heidegger, Kierkegaard, Nietzsche, Sartre; e as psicologias de Binswanger, Minkowsky, Straus, Gebsattel, etc. Tais considerações traçam uma forte linha de diferenciação nos embasamentos teórico-epistemológicos de May se comparados às bases de outros psicólogos humanistas.

Consoante a estas reflexões, May (1980) invoca o nome de William James como um pioneiro do pensamento existencial nos EUA. Este parece-nos um empreendimento arriscado, uma vez que esta tese é difícil de ser comprovada. May afirma que tal "pensamento existencial" em James surgiu após dificuldades pessoais vividas por este psicólogo em determinado momento de sua vida. Existe a suspeita de que James tenha tido contato coma filosofia de Kierkegaard na sua juventude quando estava na Europa. Mas não há provas disso. Invocar os reveses da vida de James nos parece um argumento fraco epistemologicamente para mostrar supostas afinidades da psicologia de James com a filosofia existencial. Porém, May assevera que as ideias de James possuem alguma sintonia com temáticas existenciais, tais como: a ênfase da experiência imediata, pré-reflexiva; a importância da vontade e da decisão pessoais; o fluxo constante da vida e da existência humanas; na interação entre essência e existência; e a importância da constituição de uma ciência do humano concreto para longe de qualquer tipo de abstracionismos. (May, 1980)

A existência humana, segundo estas fortes influências existenciais que marcaram a formação de May com Tillich (inclusive posteriormente), não pode ser despregada daquele que a vive e pensa. Barrocas (s/d) percebe algo singular em May: dentro de uma perspectiva geral do devir humano, Rollo May ousa convergir pensadores difíceis de aproximar, como Nietzsche, Schopenhauer, James ou Husserl. Portanto, e ainda de acordo com Barrocas (s/d), o que importa no pensamento existencialista de May é o Ser da experiência imediata, ou seja, o que é vivido como sentido. May procura compreender todos os autores que explora nesta direção interpretativa. 
Outro aspecto relevante nas diferenciações entre May em relação a outros psicólogos humanistas estadunidenses é a sólida familiaridade de May com a psicanálise freudiana e com certo ramo dissidente feita nos EUA. Primeiramente, Alfred Adler (quando May se encontrava na Europa), posteriormente Karen Horney, Harry Stack Sullivan e Erich Fromm. Ou seja, May possui uma forte sua influência, digamos, Neo-Freudiana.

Deste contato com a Psicologia Individual de Adler defendemos a hipótese (a qual necessita maior investigação) de que May tenha absorvido a convicção daquele psicólogo de que o humano se expressa no mundo através da luta incessante para impor seu plano de vida pessoal (algo como o projeto existencial que Sartre descreve no existencialismo) em meio às exigências despersonalizantes da vida social. Deste modo, as finalidades, as metas colocadas pelo próprio humano, estão na base das motivações humanas. Para este fim, as forças do Eu (Ego) procuram expandir-se na direção de uma autonomia e para longe de qualquer complexo de inferioridade (conceito criado por Adler) (Mueller, 1971). Este papel preponderante do $E u$, em detrimento das injunções inconscientes descritas pela psicanálise freudiana, encontrará eco na futura Psicologia Existencial de May.

No que tange à formação específica de May nos EUA, ele mesmo nos diz que foi "treinado" dentro do modelo psicanalítico da "escola interpessoal ou neofreudiana" (MAY, 1977, p. 95). Como ele fez seu "treinamento" no William Alanson White Institute of Psychiatry, Psychology and Psychoanalysis, esta "escola interpessoal" se refere claramente aos trabalhos de Harry Stack Sullivan. Entretanto, tais influências merecem um melhor esclarecimento para que se possa perceber sua relevância na constituição da Psicologia Existencial de Rollo May.

Os neofreudianos se diziam "psicanalistas". Estritamente falando, não o eram, pois estavam mais inclinados a perceberem o desenvolvimento do humano, do psiquismo e seus conflitos imbricados à cultura social e as condições de vida dos centros urbanos, minimizando a influência da libido recalcada postulada por Freud, sendo por isso, conhecidos também como "culturalistas” (Mueller, 1971). Com base nesta premissa, compreendiam o Ego como uma instância psíquica privilegiada e independente em relação $I d$, nem submisso aos apelos pulsionais deste. É justo dizer, portanto, que se trata de Psicologias do Ego e não de psicanálise, haja vista que o papel da sexualidade (sumamente valorizado por Freud) foi suprimido pelo pensamento conservador norte-americano. Isso leva a desconsiderar o Inconsciente como instância fundamental, colocando o Ego e a Consciência nos papéis privilegiados no drama humano.

A psicologia de Sullivan, no que nos interessa aqui, deteve sua atenção nos aspectos interpessoais das relações psicoterapêuticas. Somando-se ao fato da experiência de May em aconselhamento e das leituras feitas naquele momento (Adler e Freud - mas também Rank - são as principais referências em seu livro sobre aconselhamento psicológico), May vai compreender o atendimento clínico de modo a convergir com as premissas existenciais.

Mesmo demarcando grandes diferenças ao que se entende por "psicanálise" ao construir sua vereda numa psicologia de cunho existencial, May não se considera "menos psicanalista" (May, 1977, p. 163) por ter assimilado uma visão de mundo e do humano heterogênea ao freudismo tradicional. Cumpre apontar que as referências a Freud na obra de May não são poucas: ele tanto usa de algumas categorias advindas da psicanálise, como, muitas vezes, critica e elogia algumas posturas de Freud, chegando mesmo a mostrar releituras de aspectos do pensamento freudiano, modificando suas conceituações para fins de ampliação da compreensão da existência humana no quadro conceitual das filosofias existenciais.

Estas considerações, longe de abranger com profundidade estas e outras influências sofridas, exemplificam bem a ousadia em que Rollo May se lança em suas reflexões. Apesar disso, quando lemos alguma obra de May em que ele se aventura a fazer considerações de ordem epistemológica e histórica, a primeira impressão que ele nos passa é a de ter feito uma leitura superficial da psicanálise, do existencialismo e da fenomenologia. Bem entendido, e em que pese a afirmação de que se considera um psicanalista, May não poderia ser considerado psicanalista nem existencialista em sentido estrito. Mas esta é uma impressão, a nosso ver, enganosa: para além de ser um superficialismo, o que May realiza são releituras; reconstruções em novas perspectivas a partir daqueles saberes, os quais serviram de suporte para a constituição de sua própria Psicologia Existencial. E como dissemos, ele pode e deve ser compreendido como um psicólogo existencial-humanista.

\section{Temáticas}

No intuito de mostrar contornos próprios da Psicologia Existencial de Rollo May, apresentaremos a interpretação dada por May tem de duas temáticas (re)elaboradas na construção de sua psicologia, a saber, a questão do Inconsciente e sua concepção do humano (sua antropologia filosófica). Certamente não será uma exposição exaustiva, mas, tão-somente, uma primeira aproximação ao universo psicológico pensado/sentido por May.

Comecemos com o conceito de Inconsciente. Em linhas gerais, a categoria do Inconsciente na psicanálise sustenta-se pela tese de que os desejos humanos foram recalcados pelo forte sentimento de culpa que os mesmos provocam. Ora, a culpa gerada por tais desejos advém do caráter sexual que os contém; e este caráter, por seu turno, tem sua base no Complexo de Édipo. A íntima ligação entre o desejo, o recalque e o Édipo constituem o núcleo daquilo que Freud nomeou de o Inconsciente. E tais desejos, quando rompem momentaneamente as resis- 
tências e a censura psíquicas, aparecem como formações do Inconsciente na Consciência. Assim, o Inconsciente freudiano implica o registro da representação das pulsões sexuais recalcadas e os conflitos aí inerentes.

Com a formação que recebeu, May conhece bem estas teses fundamentais que colocam o Inconsciente como categoria pilar da psicanálise. Entretanto, pelas suas influências neofreudianas, ele vai reler este conceito de forma bem diferente.

May nos alerta que se nos livrarmos da hipótese do inconsciente "ficaremos mais empobrecidos, ao perdermos grande parte e significação da experiência humana" (MAY, 1977, p. 131). Este apreço por tal noção mostra como May, ao contrário do pensamento vigente na Psicologia Humanista, não se dedicava a dizer que Freud estava "errado em tudo" e que a psicanálise é só sexo e incesto. Seguindo uma linha de raciocínio própria da Psicologia Humanista, a qual sustenta que a Consciência é a parte essencial do modo de ser do humano (Carpintero, Mayor \& Zalbidea, 1990), May, ainda que reconheça a grande contribuição do gênio de Freud para a psicologia, contempla a herança freudiana na contramão da psicanálise tradicional ao enunciar que "Freud ampliou tremendamente o domínio da consciência humana” (May, 1977, p. 120).

Ora, as preocupações de Freud eram com o Inconsciente e não com a Consciência. Com isso May subverte a imagem tradicional do pai da psicanálise e alinha-se à tradição humanista que ajudou a fundar. Para May, o mérito de Freud foi ter mostrado que existem "forças que são muito mais vastas, mais profundas e significativas" (1977, p. 121) as quais nos fazem questionar a visão do humano na Psicologia Humanista baseada em um suposto racionalismo soberano totalmente autoconsciente e autônomo. Arriscamos dizer que May até concordaria com a terceira ferida narcísica desferida pela psicanálise freudiana, o que contraria a imagem do humano apregoada pelo humanismo em psicologia.

Conceitualmente falando, May prefere falar em "potencialidades inconscientes da experiência” (May, 1977, p. 121) do que colocar a ênfase de se pensar o Inconsciente como "instância psíquica” dependente do registro da representação. Inclina-se a percebê-lo como "experiência inconsciente”. O que é digno de atenção aqui, é que May coloca que tais experiências têm por base a consciência e não contrário como acontece na psicanálise.

No entender de May, o humano, ainda que pese a possibilidade de possuir dimensões "mais profundas", ele pode ascender a uma “conscientização", isto é, à percepção clara de que existe uma distância (não uma cisão) entre nós e o mundo que nos rodeia. Conscientização, aqui, significa dar-se conta das possibilidades existenciais que estão em curso em determinado momento. Uma das tarefas da psicoterapia seria tornar conscientes este contexto e seus sentidos possíveis. Esta configuração nova não havia sido percebida claramente; portanto, as "experiências inconscientes" são as potencialidades de traçar um novo percurso existencial. Ciente disso o humano pode tomar tais potencialidades e torna-las concretas como uma criação existencial de si mesmo. Amparado por tal perspectiva, May percebe a Consciência, o Eu, a Personalidade - o humano, enfim - como um ente que persegue a realização de seu próprio ser.

Por fim, sobre o inconsciente, May é enfático.

Devemos, desde já, redefinir o conceito. Não podemos dizer o inconsciente, visto que nunca é um lugar. Tampouco são coisas, no sentido de entidades inconscientes; as coisas não são reprimidas; mas os processos e as potencialidades são. Proponho a seguinte definição: Experiência inconsciente são as potencialidades de ação e percepção que a pessoa não pode ou não quer tornar concretas (May, 1977, p. 133).

Acerca de sua concepção do humano, Rollo May certamente é tributário do modo como a Psicologia Humanista estruturou sua antropologia. Uma visão de humano muito particular, claramente positiva e otimista.

A Psicologia Humanista percebe o humano como alguém que merece uma extrema valorização, posto que detém uma espécie de potencial, de uma força que lhe é inerente e propiciadora de seu crescimento biopsíquico. Esta "força" foi chamada, entre outros nomes, de capacidade de autorrealização. Assim, na visão da Psicologia Humanista, o humano possui em si mesmo um poder de mudança interna que o capacitaria a expressar seus sentimentos, pensamentos, bem como seu comportamento, tudo em congruência com as demandas do mundo, na busca de uma existência que seja perenemente autêntica e autoconsciente. Este "potencial” quer sempre se atualizar cada vez mais enquanto houver vida e projeto para a própria existência. Considera que tais dimensões, as quais enalteceriam o humano, conferindo-lhe sua dignidade, foram desprezadas e/ou esquecidas pela psicanálise e pelo behaviorismo, apresentando, em contraposição a estas, um conceito do humano mais positivo, por isso, e o mais otimista possível. A Psicologia Humanista trouxe de volta, assim, os valores e uma postura ética, intimamente humana, no ímpeto de reconstituir um novo modo de perceber o humano como singular, concreto e único.

Esta concepção do humano converge com os postulados que James Bugental (citado por Carpintero, Mayor \& Zalbidea, 1990, p. 75s) colocou para American Association for Humanistic Psychologv, referindo-se a que qualidades o humanismo em psicologia deve dirigir sua atenção quando trata destte humano. Diz ele que

1. O homem como homem é maior que a soma de suas partes. Ele deve ser considerado como algo mais que o produto ou soma de várias partes e funções.

2. O homem conduz sua existência em um contexto humano. Sua natureza se expressa em suas relações com outros seres humanos. 
3. O homem é consciente. A consciência forma a parte essencial do seu ser.

4. O homem tem capacidade de escolha. A consciência faz com que o homem não seja um mero espectador de seu destino, mas atuante de suas experiências.

5. O homem é intencional. A intencionalidade é a base sobre a qual o homem constrói sua identidade.

Embora esta visão do humano fosse compartilhada por vários humanistas (ainda que com algumas sutis diferenças), podemos afirmar com segurança que os nomes de Maslow e de Rogers foram os que mais decididamente contribuíram com suas ideias e práticas científicas para a sustentação e confirmação da potencialidade do humano e da sua tendência a se atualizar e crescer.

Do exposto, não é difícil compreender que a Psicologia Humanista influenciou (e ainda influencia) para um renovado despertar de valores e posturas éticas as quais levam a uma mais completa compreensão do humano, levando em conta sua potencialidade, sua responsabilidade, sua liberdade de escolha e sua tendência a realizar-se. Nesta valorização do humano não se deve esquecer, sobretudo, do seu caráter interpessoal (a relação com os outros) e a relação com o mundo circundante social e cultural. Uma autoconsciência não diz respeito somente ao humano e seus sentidos particulares, pessoais; envolvem outros sentidos que incluem o mundo e os outros com os quais nunca se deixa de estar em relação.

Campos (2006) assinala que o humano da Psicologia Humanista deve ser visto "como um ser essencialmente livre e intencional, devendo ser entendido primordialmente pela sua dimensão consciente e, sobretudo, pela vivência de suas experiências presentes" (p.252). Pode-se resumir, sobre modo de ver o humano, que o humanismo em psicologia tinha (e tem) como pano de fundo, uma visão de homem como um ser em busca constante de si mesmo, que vive um contínuo processo de vir a ser e que apresenta uma tendência "natural” para se desenvolver. “(...) A meta principal desses psicólogos se volta para a transformação da ciência, da consciência, dos valores e das atitudes, tendo como finalidade básica a busca de novos espaços e novos canais de expressão para o indivíduo." (Campos, 2006, p. 252)

Entretanto, May desenha outros contornos a esta concepção humanista, fruto de suas influências existenciais. Não se trata de uma concepção contraditória, mas inclusi$v a$ a àquela visão. Segundo ele " $a$ abordagem existencial sustenta que devemos formular a questão da natureza do homem como homem, isto é, a questão ontológica" (May, 1977, p. 101). E, a nosso ver, é uma visão mais lúcida e realista à existência humana.

Das influências existencialistas, Tillich nos parece sair na frente em relação a outras filosofias. De acordo com Goto (2004), Tillich, amparado pela filosofia tardia de Schelling, será levado a correlacionar as categorias de "essência” e "existência”, as quais passaram a ocupar o seu pensamento filosófico e teológico. Tillich fundamenta sua concepção teológica na íntima relação entre estas categorias, considerando que uma não poderia subsistir sem a outra e sem privilegiar um dos pares. Tillich não assume nem uma postura essencialista, nem existencial. Ele mesmo nos assevera que

Não haveria árvores se não existisse a estrutura da "arvoridade" eternamente, mesmo antes da existência das árvores, e também depois que as árvores entram na existência. $\mathrm{O}$ mesmo se pode dizer a respeito do homem. A essência do homem é eternamente dada antes de seu aparecimento na terra. É dada potencialmente ou essencialmente, e não existencialmente ou de fato. Estamos num ponto decisivo do pensamento filosófico (Tillich, citado por Goto, 2004, p. 100).

Mesmo conhecendo filosofia existencial de Sartre (diametralmente oposta a de Tillich nesta especificidade), ao que parece isso não lhe trará grandes conflitos para May a fim de constituir sua própria imagem do humano, aproximando-se de Tillich.

Partindo de um esclarecimento conceitual do que ele compreende por "existencialismo", May (1980) começa por relembrar a raiz latina do termo "existência", entendendo-a como emergir, surgir, devir. Mas sua reflexão se concentra na oposição deste termo com outro: "essência". Dizer que o humano é existência implicaria que ele não ter essência nenhuma? Dentro do âmbito da Psicologia Existencial esta pode ser uma tendência marcada. Porém, May não se contenta com isso.

Apoiando em uma longa citação de Tillich (que ele não informa a fonte) e trazendo à baila a premissa básica do existencialismo sartreano (A existência precede a essência), May sugere que, se o humano é aquele cuja "natureza” é o seu "poder criar a si mesmo" (May, 1980, p. 15), a pergunta sobre o modo de ser deste movimento criativo de si impõe a tese implícita de uma provável essência. Em verdade, May não resolve este problema: ele não se dedica a refutar as explicações teóricas essencialistas em várias escolas psicológicas. Limita-se a dizer que elas não conseguem dizer tudo do humano, sobrando "algo" de "irredutível" a ele. Este "algo" é o "elemento de decisão consciente e da responsabilidade" (May, 1980, p. 16). É como se a consciência pudesse engendrar a si mesma, engrandecendo o humano de tal maneira que seus "mecanismos psicológicos" explicar-se-iam em sua amplitude tendo por base uma concepção antropológica que sugere uma espécie de "capacidade de autodirecionamento" do humano, ainda que impere um certo mal-estar. Algo que ainda possui certa convergência com a visão de humano da Psicologia Humanista. Mas o que seria esta natureza essencial do humano? Tillich, mais uma vez, traz a resposta a esta pergunta.

Em seu artigo "A concepção de homem na filosofia existencial”, Tillich não se preocupa em fazer recense- 
amento de vários filósofos e seus pontos de vista exclusivamente existenciais. Sempre dentro do âmbito da teologia, ele prefere falar de sua própria perspectiva antropológica, ao mesmo tempo, atravessada por um olhar ontológico. Paradoxo de sua filosofia: uma aproximação tensa não-sintética de ser e não-ser que justifica um certo conceito do humano.

Uma característica que se delineia com clareza na descrição ontológica do humano é a ênfase que Tillich coloca na "criatividade fundamental", base do humano livre e do mundo no qual vive e está entranhado, dependente dele para fazer-se, constituir-se nas ações da liberdade. O humano, criatura e imagem de Deus, é a "criatura criativa", misto de infinito e finitude; unidade e dissolução; eterno e temporal trágico, que tenta elevar-se ao universal, possibilidade implicada na liberdade. Criatividade e tragicidade misturam-se tal como "essência" e "existência", portanto. Com a afirmação de que o humano "é uma unidade e uma totalidade" (Tillich, 2010, p. 229), Tillich deixa claro que toda investigação possível desta "unidade" deve privilegiar vários métodos, devendo os mesmos dialogar entre si a fim de descreverem a "natureza humana", como ele diz.

Porém, segundo Tillich, tudo o que é humano decorre da liberdade, categoria distintiva em relação a outros entes não-humanos. Assim, descrever a unidade essencial humana não é enveredar-se em discussões acerca do livre-arbítrio, mas descrever uma "doutrina da liberdade”. Entretanto, como a liberdade comporta um caráter ambíguo, Tillich agrega uma "natureza existencial" ao humano (eco que pode ser escutado correlativamente nas teses de May vistas acima sobre "essência" e "existência”). Tillich sustenta que estes dois pontos de vista (essencial e existencial) têm de ser contemplados sem prevalência de uma delas. Com esta descrição da liberdade, Tillich quer encontrar elementos para esclarecer vários conceitos teológicos (como a culpa e a salvação) a ela relacionados.

Permeado pela presença tácita de Kierkegaard em suas reflexões, Tillich nos diz que o humano "é o mais individual do que qualquer outro ser. Ele é o indivíduo completo porque, por outro lado, ele é um 'eu' definido" (Tillich, 2010, p. 231). Mas ele também é "espírito", isto é, uma "unidade dinâmica" de caracteres opostos, mas que o constituem, como diria o pensador danês, numa dialética desprovida de uma síntese possível.

Enquanto ente livre, Tillich percebe que no humano sua "primeira e fundamental" característica: ele é livre porque é criativo: ele pode criar algo novo para transcender uma situação qualquer; para transcender a si mesmo em direção a uma unidade entre universalidade e individualidade (que é o encontro com o outro humano); na criação proposital de objetos e símbolos significativos (criação cultural); e, por fim, com a possibilidade de "jogar com seu mundo e consigo mesmo" (Tillich, 2010, p. 231) constituindo-se para além de si.
Porém, tais modos criativos da liberdade sempre comportam riscos: o humano pode perder-se nas escolhas que toma em cada uma destas dimensões da ação livre, indo (paradoxalmente) contra a própria liberdade e caindo na servidão: lugar próprio da angústia ante as possibilidades que se lhe abrem. É quando o humano percebe que "tem medo de não usar essa liberdade e ainda tem medo de usá-la” (Tillich, 2010, p. 232). O modo da servidão não faz do humano "menos humano"; mas é a vigência de uma ambiguidade originária de sua essência livre, transformando-se em criatividade "trágica e pecaminosa” (Tillich, 2010, p. 232)

Nesta reunião de aspectos ontológicos ligados à liberdade que Tillich empreende, a criatividade humana é a vigência própria de uma inquietação e errância diante da situação angustiada do isolamento "frente ao abismo da insignificância e da ameaça de aniquilação ao seu redor" (Tillich, 2010, p. 233). O humano tenta fugir desta condição de angústia (a qual lhe proporciona certo sentimento de solidão e melancolia diante da morte) ao empreender corajosamente as suas várias formas expressivas culturais e civilizatórias, tentando dar sentido ao que lhe concerne. Para Tillich só o humano vivencia a angústia e a coragem na sua existência.

A tragédia está nas tentativas reiteradas e corajosas do humano escapar às dores de seu existir. Por não conseguir escapar de sua situação existencial universal, ontologicamente o humano permanece na sua tragicidade e liberdade. Como "unidade" e "dissolução" (essência e existência), Tillich não recai num "pessimismo destrutivo sem critérios e sem esperanças (perspectiva somente existencial), nem num "otimismo superficial sem revelação e sem graça" (perspectiva somente ligada à sua "natureza”) (Tillich, 2010).

Explicitada a filosofia de Tillich acerca do humano e fortemente influenciado por ela, a abordagem existencial que May defende se pauta numa prévia formulação ontológica "da natureza do homem como homem" a fim de que possa delinear para si suas hipóteses científicas de trabalho e compreensão da existência. Sobre esta apropriação metodológica feita por May, Silva e Holanda (2010, p. 77) também a apontam ao atestarem que, em Tillich, "a ontologia precede a toda formulação científica ou a qualquer aproximação cognitiva da realidade”. Assim, as contribuições de filosófico-teológicas de Tillich foram, a nosso ver, muito mais marcantes do que as próprias filosofias européias, em que pese a importância delas na constituição da psicologia de Rollo May.

\section{Palavras Finais}

Após este brevíssimo percurso, certamente não foram exploradas (ou esgotadas) as diversas chaves de leitura possíveis à Psicologia Existencial de Rollo May acerca da 
sua epistemologia e das temáticas aqui desenvolvidas. Outros caminhos são igualmente possíveis de encontrar luz: Eis algumas: a construção conceitual da angústia (traduzida em língua portuguesa por 'ansiedade') em relação às concepções existenciais e psicanalíticas; como a questão da criatividade em Tillich (construída filosoficamente) repercute no fenômeno psicológico da criação artística; um aprofundamento da concepção do humano em May (aqui apenas esboçada) nos diversos momentos de seu percurso epistemológico-existencial; como o conceito de coragem (mais uma categoria tillichiana) ressoa nas formulações de May sobre a psicoterapia; as influências da psicologia interpessoal de Sullivan no modo de se fazer psicoterapia em May; sua concepção de ciência; ou mesmo a apreensão do pensamento husserliano ou de Nietzsche, por exemplo. Estas, entre outras, são apenas perguntas possíveis a partir das quais hipóteses de pesquisa podem ser formuladas.

Sobre sua própria psicologia, o curioso é que May, em sua obra Psicologia e Dilema Humano (publicado em 1967), diz não acreditar em uma "escola especial de terapia que possa ser colocada numa categoria de 'existencial'. Como emprego o termo 'existencial' refere-se a uma atitude aos seres humanos e a um conjunto de pressupostos sobre esses seres humanos" (May, 1977, p. 118). Ora, alguns anos antes (em 1960), ele organizou um livro cujo o nome é justamente "Psicologia Existencial" no qual ele participa escrevendo sobre suas origens e pressupostos, bem como sobre o fundamentos existenciais da psicoterapia. Como ele pode dizer que não existiria uma "escola" se ele mesmo constitui uma versão da mesma nos EUA?

Amparado por releituras e interpretações das filosofias existenciais (Kierkegaard, Nietzsche, Sartre, etc.); da fenomenologia; da filosofia teológica de Tillich; da herança psicanalítica de Freud; e de um certo modo de fazer psicologia fenomenológica como foi empreendido por Binswanger, Straus ou Minkowsky, a psicologia de Rollo May, podemos dizer com propriedade e mesmo correndo o risco sermos repetitivos, é uma Psicologia Existencial não por uma adesão sem críticas a algum daqueles sistemas de pensamento em particular, mas por enfatizar a "realidade da experiência imediata no momento presente" (MAY, 1980, p. 17): ela não é uma "psicanálise existencial", porém, trata-se de uma psicologia da vivência plenamente consciente, munida de uma atitude que se quer compreensiva do modo próprio do devir humano. Sua postura de protesto e tentativa sempre retomada de compreensão é patente, ainda que muitos de seus posicionamentos epistemológicos e psicoterapêuticos não se alinhassem por completo ao ideário da Psicologia Humanista.

O contínuo contato com as influências acima mencionadas; a vivência de quase-morte durante sua enfermidade; a reflexão que levou a termo sobre a angústia e a tragicidade que concernem ao humano; tais acontecên- cias em sua biografia fizeram com que May se dedicasse com toda força para a constituição de uma psicologia preocupada com este mundo desarticulado de sentido para o humano: um mundo da técnica (pobre de sentido) que se sobrepõe a um sentido existencial. Isso faz com que May não compartilhasse de "psicologias do ajustamento" e da "felicidade tranquila" (relativamente comuns no contexto norte-americano) que faz do humano um ser conformado e aparentemente "desprovido de seu devir", criação e coragem.

A Psicologia Existencial de Rollo May é uma peça rara entre as psicologias existências-humanistas. Rara e bem diferente. May era um híbrido; um rico paradoxo cuja riqueza, a nosso ver, precisa ser resgatada. É preciso fazê-la falar, dialogar, formar, destruir e gritar.

\section{Referências}

Barrocas, R. L. L. (s/d). A "influência difusa" da fenomenologia nas psicologias humanistas. Texto inédito.

Boainain Júnior, E. (1998). Tornar-se transpessoal: transcendência e espiritualidade na obra de Carl Rogers. São Paulo: Summus.

Campos, R. F. (2006). Ética contemporânea: os anos 60 e o projeto de psicologia humanista. Epistemo-somática, v.3, 2, 242-260.

Carpintero, H., Mayor, L., \& Zalbidea, M. A. (1990). Condiciones del Surgimiento y desarrollo de la Psicología Humanista. Revista de Filosofia. Editorial Complutense. Madrid. 3(3), 71-52.

Frick, W. B. (1975). Psicologia humanista: entrevistas com Maslow, Murphy e Rogers. Rio de Janeiro: Zahar Editor.

Goto, T. A. (2004). O fenômeno religioso: a fenomenologia em Paul Tillich. São Paulo: Paulus.

May, R. (1973). Eros e repressão: amor e vontade. Petrópolis: Vozes.

May, R. (1977). Psicologia e dilema humano. $3^{\mathrm{a}}$ ed. Rio de Janeiro: Zahar Editor.

May, R. (Org.). (1980). Psicologia existencial. Rio de Janeiro: Globo.

May, R. (1987). Liberdade e destino. Rio de Janeiro: Rocco.

May, R. (1988). A descoberta do ser. São Paulo: Rocco.

May, R. (1992a). A coragem de criar (10ª ed.). Rio de Janeiro: Nova Fronteira.

May, R. (1992b). Minha busca da beleza. Petrópolis: Vozes.

May, R. (1992c). A procura do mito. São Paulo: Manole.

May, R. (1999). O homem à procura de si mesmo (26 ed.). Petrópolis: Vozes. 
May, R., Angel, E., \& Ellenberger, H. (Orgs.) (1977). Existencia: nueva dimension em psiquiatría y psicología. Madrid, Editorial Gredos.

Muller, F. L. (1971). A psicologia contemporânea (2a ed.). Lisboa: Publicações Europa-América.

Rogers, C. R. (1987). Psicoterapia e consulta psicológica. São Paulo: Martins Fontes.

Serrano, D. (2008). Rollo May. Disponível em < http://www.portaldapsique.com.br/Artigos/Rollo_May.htm>.

Silva, G. V. \& Holanda, A. F. (2010). As fronteiras da finitude: um panorama do diálogo de Paul Tillich com a psicologia. Memorandum, 18, 68-83.

Tillich, P. (2010). A concepção do homem na filosofia existencial. Revista da Abordagem Gestáltica. XVI(2), 229-234.
Carlos Roger Sales da Ponte - Psicólogo; Mestre em Filosofia e Mestre em Psicologia pela Universidade Federal do Ceará (UFC). Atualmente é Professor Assistente do Curso de Psicologia da Universidade Federal do Ceará (Campus de Sobral) e Coordenador do grupo VEREDAS Círculo de Estudos em Fenomenologia, Existencialismo e Psicologia Humanista. Endereço Institucional: Universidade Federal do Ceará (Campus de Sobral). Av. Lúcia Sabóia, 215 - Centro - CEP: 62.010-830

- Sobral-CE - Brasil. E-mail: jardimphilo@yahoo.com.br

Hudsson Lima de Sousa - Graduando do Curso de Psicologia da Universidade Federal do Ceará (Campus de Sobral). E-mail: hudssonl@yahoo.com.br

Recebido em 10.02.11

Primeira Decisão Editorial em 20.05.2011

Aceito em 18.07.11 